\title{
La Economía Moral
}

\author{
Wilson Marcos ORTIZ TREVIÑOS
}

\section{RESUMEN:}

"Economía moral" fue una expresión acuñada por Edward Thompson, para evidenciar que el sujeto no es un agente pasivo incapaz de intervenir en la estructuración del mercado bajo una óptica moral, al margen del paternalismo gubernamental. Pone de manifiesto que las protestas han sido, por lo general, explicadas bajo las variables: pobreza e ignorancia; aun cuando la gente no protestara para destruir los medios de producción y comercialización, sino más bien como refiere Thompson "que el productor ganará, pero no lucrará". La verdadera pobreza e ignorancia residía en los análisis simplistas de la época. Con este artículo buscamos reflexionar en torno al estrecho vínculo de dos importantes términos: moral y economía.

Palabras clave: economía, moral, protesta, consumidor, productor, paternalismo Para el economista puede resultar más cómodo hablar de crecimiento, déficit presupuestal, balanza comercial negativa, inflación, hiperinflación, desregulación de precios, tipo cambiario, etcétera, pasando por alto que en todos y cada uno de tales conceptos están involucradas historias humanas, particulares e intensas; auténticas protagonistas de la dinámica socioeconómica. La caída de un punto porcentual en el PBI puede significar la ruina de miles de vidas, así como el crecimiento sostenido de un país puede traducirse en la superación de la pobreza para otros miles. Al ser la economía una actividad humana no está exenta de otras manifestaciones también humanas como la reflexión moral y el condicionamiento ético. La separación de ambas o la intención de su desvinculación, lo que podríamos llamar: objetivación, no es connatural a su relación; por el contrario, es el resultado de un nuevo modo de entender el mundo'. También es cierto que

1 Con el surgimiento del positivismo lógico, la objetivación de las ciencias pasó a ser una de las pretensiones máximas de su programa. La ética parecía no tener cabida en una estructura general para la ciencia unificada, librada al fin de la ética y de las inconveniencias morales. Pese a los debates y enorme cantidad de críticas que tales pretensiones merecieron; no faltaron quienes impulsaron su expansión y consolidación. El espíritu de la reforma positivista influyó en el análisis de teóricos sociales. Con rezagos de ello o no, la historia se planteó un análisis retrospectivo sobre variables económicas y el modo de influir o condicionar las respuestas morales, pasó a ser inverso: la moral como variable para entender, influir o condicionar las respuestas económicas. 
no todas las sociedades responden del mismo modo a los mismos estímulos. La sociedad británica se ha caracterizado por imponer sus propias tradiciones ${ }^{2}$ y exportarlas al mundo. En el siglo XVIII, Inglaterra estaba en pleno tránsito, pasaba de una economía feudal a una liberal; en ello, puede observarse un papel distinto de la gente en relación al quehacer económico.

En 1979 Edward Thompson ${ }^{3}$ presentó un análisis sobre la realidad inglesa en dicho tránsito, ello nos permite observar cómo la gente común legítima su intervención en la estructuración económica a través de la protesta reguladora de precios. Este modo de intervención era el resultado de una idea tradicional sobre las normas y obligaciones sociales y de las funciones económicas propias de los distintos sectores dentro de la comunidad que, tomadas en conjunto, puede decirse constituían la "economía moral" de los pobres. Un atropello a estos supuestos morales, como la privación en sí, configuraba la ocasión habitual para la acción directa de la muchedumbre, acción dirigida a reestablecer el equilibrio en el intercambio. El alza de los precios es un factor determinante para entender la economía moral, pues fungía de catalizador de la acción en el habitante común y corriente, dado que tal alza alteraba la cotidianidad y condicionaba la normal distribución del gasto familiar.

Lejos de la visión paternalista que, por lo usual pretende simplificar este tipo de fenómenos sociales achacando su origen a la "ignorancia", la "rudeza de las costumbres" o "la falta de educación", tenemos frente a nosotros un poblador con una muy sensible y elevada conciencia de consumidor. La dinámica que tenía lugar no podía ser explicada en términos lacónicos, tampoco podía calificárseles como manifestaciones políticas o apolíticas con intereses desestabilizadores. Tales fenómenos sociales tenían que ser asumidos como complejos ${ }^{4}$. Entre 1709

2 Tengamos en cuenta la tradición legal anglosajona distante a la influencia del derecho romano.

3 Thompson tiene formación marxista. Sin embargo, ello no impide que abandone o cuestione conceptos claves del marxismo, como el de "clase". Desde su visión neomarxista, para ser más preciso, no es posible constreñir los procesos flexibles y además cambiantes a un concepto estático: "Todavía más, la noción de clase entraña la noción de relación histórica. Como cualquier otra relación, es un proceso fluido que elude el análisis si intentamos detenerlo en seco en un determinado momento y analizar su estructura. Ni el entramado sociológico mejor engarzado puede darnos una muestra pura de la clase, del mismo modo que no puede dárnosla de la deferencia o del amor. La relación debe estar siempre encarnada en gente real y en un contexto real. Además no podemos tener dos clases distintas, cada una con una existencia independiente, y luego ponerlas en relación la una con la otra" (Thompson, 1989, pág. prefacio). La posibilidad de que Thompson en su formación y producción académica sea capaz de superar el dogmatismo ideológico, hace de sus análisis elementos de mayor valía para entender los cambios y las continuidades.

4 Complejidad entendida en términos de Morín: “[Complejidad] su definición primera no puede aportar ninguna claridad: es complejo aquello que no puede resumirse en una palabra maestra, aquello que no puede retrotraerse a una ley, aquello que no pue- 
y 1801 la sucesión de "insurrecciones", "levantamientos de pobres" o "motines", son una constante. Pero, coinciden con el empoderamiento de Inglaterra como potencia agrícola de reconocida calidad productiva. Si la versión paternalista del asunto quiere relacionar "ignorancia" = "motín", bajo qué entendido relacionaría "alta calidad productiva" = ignorancia. Esto último pone en evidencia la clásica limitación explicativa del reduccionismo paternocultural.

Asimismo, al igual que en Francia ${ }^{5}$, en Inglaterra las grandes mayorías sobrevivían gracias al consumo, casi exclusivo de pan $^{6}$. Durante esta época las autoridades promovieron el consumo de un pan "barato" elaborado con insumos de evidente menor calidad, pero a un precio comparativo muy por debajo de lo previsto por el consumidor; sin embargo, el pan producido bajo tales auspicios era tan tosco y de tan magra textura que los mismos panaderos lo producían en ínfimas cantidades, las que ni aun así se agotaban. La gente tendía a sospechar de este tipo de productos, asumía por el aspecto, el sabor y la disposición que podía ser hasta venenoso (Girdler, 1800, pág. 88).

El productor en su lógica empresarial sabía que la gente no pondría en riesgo la salud de su familia, por muy pobre que fuera. Por ende, la gente optaba por sacrificar el consumo de otros bienes o productos con tal de optar por el pan de mayor calidad aun cuando el precio fuese mayor, lo que tenía un efecto doble, por un lado representaba un pequeño margen de mayor ganancia para productores y vendedores y algo más de tranquilidad alimentaria en el consumidor. Pese a ello, las autoridades trataron de regular la producción y el consumo de este tipo de diferenciaciones, promovieron ordenanzas para obligar a los molineros a producir pan barato; ante la insistencia en tales propósitos la gente, liderada por mujeres, salía a las calles, avanzaba hasta panaderías y molinos y destruía algunas de las herramientas usadas en la producción, bajo la amenaza de mayores represalias si se insistía en seguir elaborando "veneno". Frente a tales rechazos, este tipo de decretos sobrevivieron solo dos meses ${ }^{7}$. Queda en evidencia que la gente ejercía sus propias regulaciones, dentro de los límites de lo "moralmente correcto", valoración que la mayoría imponía como mudo consenso.

de reducirse a una idea simple. Dicho de otro modo, lo complejo no puede resumirse en el término complejidad, retrotraerse a una ley de complejidad. La complejidad no sería algo definible de manera simple para tomar el lugar de la simplicidad. La complejidad es una palabra problema y no una palabra solución (Morin, 1990, págs. 21-22)

5 Fueron épocas de muy malas cosechas, lo que restringió el consumo y generalizó el hambre (Prentice, 1946)

6 "Cuando los precios eran altos más de la mitad de los ingresos semanales de la familia de un trabajador podía muy bien gastarse exclusivamente en pan" (Thompson, 1979, pág. 70)

7 A estos decretos se les conoció en su época como "Decretos del pan negro" o "Decreto del veneno" 
El paternalismo gubernamental trataba de favorecer al pobre, condicionar la ganancia del mayorista y contener el acaparamiento, regateo y monopolio ${ }^{8}$. A la luz de tal esquema, la intermediación era pasible de rechazo y restricción legal, ello debido a la lógica que gobierna su quehacer y que, a entender de autoridades y comunidad, era inmoral, molineros y panaderos no son solo agentes económicos, tampoco son solo comerciantes, son ante todo: servidores de la comunidad y como tales "trabajan, no para lucrarse, sino para lograr una ganancia razonable" (Thompson, 1979, pág. 72). Sin embargo, mucho de este voluntarismo social, que sin duda funcionó por décadas como un sistema amparado en la tradición como derecho consuetudinario, vio florecer estructuras paralelas que no solo distorsionaban las ganancias también la regularidad del abastecimiento y el consumo: florecieron el contrabando y los mercados negros.

Tres aspectos hay que tener muy en cuenta al revisar los hechos ya mencionados. En primera instancia, para las grandes mayorías la economía no era una actividad alejada de la reflexión ética ni mucho menos de la acción moral. Si el desbalance del margen de ganancia, en relación al precio, ponía en aprietos la economía de las familias necesitadas, entonces la protesta estaba asegurada hasta que se restableciera la armonía. Segundo, la gente tampoco disociaba: calidad - producto - precio; comprendía que el producto de mayor calidad tenía que costar más y lo prefería aun cuando ello significase sacrificar el consumo de otros productos de su habitual canasta. La gente toleraba tales variaciones en la medida que el precio fuera moral, en relación a sus posibilidades adquisitivas. Tercero, la protesta no buscaba destruir el sistema o reemplazarlo por otro, buscaba que siguiera funcionando como tradicionalmente lo había hecho ${ }^{9}$, los ataques a molinos no dañaban irremediablemente sus medios de producción, era más una sanción moral.

Siendo así, se hacen pertinentes algunas reflexiones a las que indirectamente nos invita Thompson. Muchas de las sociedades actuales se debaten entre los rezagos de ese paternalismo económico, llámesele como se guste: "estatismo", "colectivismo", "intervencionismo", etcétera y todas aquellas categorías, seguramente mucho más precisas para describir la intervención política en asuntos de intercambio comercial; decía, que nuestras sociedades se debaten entre ello y la desregulación total "entre la mano invisible del mercado" de Smith y la, precisamente "invisible mano del mercado" porque no existe o no está ahí ${ }^{10}$. En ese punto, empiezan a notarse radicalidades en los discursos que

8 Reinado de Eduardo VI de Inglaterra

9 Recuerda en parte las protestas en el Perú, como bien lo anota un sociólogo extranjero: En el Perú la gente protesta no para tumbarse el sistema sino más bien pidiendo que el sistema funcione.

10 "Los galardonados [con el Nobel de Economía] del año pasado implicaron que los mercados no eran, en general, eficientes; [...] Mano invisible de Adam Smith - la idea de que los mercados libres llevan a la eficiencia como guiado por fuerzas invisibles - es invisible, al menos en parte, porque no está allí” (Stiglitz, 2002) 
defienden ambas posturas, pero también rarezas ideológicas ${ }^{11}$. No olvidemos a dónde llevó la desregulación a los Estados Unidos en el año 2007 (Nadal, 2008). Esas crisis fueron inmorales, los mecanismos para revertirlas, antiliberales e inmorales también ${ }^{12}$. De tal o cual perspectiva ha dependido la marcha de economías emergentes así como las crisis cíclicas de las economías del primer mundo. Recordar la descripción de Thompson rehabilita la variable sujeto agente, nos recuerda su actuación como regulador, no solo del consumo, también de la calidad de dicho consumo, sus protestas organizadas no buscaban destruir al productor, tampoco arruinarlo, buscaban que "no los envenenaran" con sus productos. Algo que sociedades como la nuestra recién ha empezado a tomar en serio en los últimos años ${ }^{13}$, y sobre lo que aún hay mucho por hacer.

Finalmente, no se puede esperar la regulación estatal como si los sujetos, individuos o ciudadanos fuésemos menores de edad a quienes hay que "ayudar" a ser humanos. La gente tiene un rol económico preponderante dentro del consumo de bienes y servicios y en tal condición debieran tener presente permanentemente la necesidad de establecer una relación moral con aquel que produce y comercia; en tanto el que produce y comercia debe también llegar al convencimiento que el margen de ganancia no puede establecerse sobre la base de vender "gato por libre" o asumir que la "ignorancia" y la compulsión del consumidor son la cualidad distintiva del producto que ofrece, su ventaja comparativa y el soporte de su plan empresarial. Economía y moral guardan ligazón estrecho, en la medida que los individuos se empoderan de la potencialidad reguladora del mercado.

11 Por ejemplo, en el Perú, quienes defienden la reducción del Estado y su no intervención en asuntos económicos, son los mismos que promueven medidas de "estimulación económica" que en el fondo son subvenciones para empresarios e inversionistas, defienden también mercados cautivos como el de las AFPs. Desde su perspectiva liberal resulta contradictorio que se rechace lo uno y se promueva lo otro. En todo caso su liberalidad puede terminar siendo percibida como discursiva y sesgada. No les caería mal una relectura de Ludwig von Mises, el más grande teórico de la economía liberal (Mises, 2011).

12 Tomar el dinero de los contribuyentes y destinarlo al rescate financiero de empresarios y empresas, ¿cómo debiera ser calificado?

13 El 02 de setiembre de 2010 se aprobó, en el Perú, el Código de Protección y Defensa del Consumidor, luego de ser postergado por el segundo gobierno aprista. http://portal.andina.com.pe/EDPEspeciales/especiales/2010/setiembre/codigo_consumidor. pdf (Perú, 2010) 


\section{BIBLIOGRAFÍA}

1. Girdler, J. S. (1800). Observations on the pernicious consequences of Forestalling, regreting and engrossing. Londres: Google books.

2. Mises, L. v. (2011). La acción humana. Tratado de economía (Décima ed.). Madrid: Unión Editorial SA.

3. Morin, E. (1990). Introducción al pensamiento complejo. Barcelona: Gedisa S.A.

4. Nadal, A. (2008). La crisis financiera de Estados Unidos. Boletín económico de ICE, Información Comercial Española, 19-29

5. Perú, G. d. (2 de Setiembre de 2010). Ley $N^{\circ} 29571$ portal.andina.com.pe. Obtenido de portal.andina.com.pe: http://portal.andina.com.pe/EDPEspeciales/especiales/2010/setiembre/codigo_consumidor.pdf

6. Prentice, P. (1946). El hambre en la historia. Argentina: Espasa-Calpe.

7. Stiglitz, J. (20 de Diciembre de 2002). There is no invisible hand. The Guardian, pág. http://www.theguardian.com/education/2002/dec/20/highereducation.uk1/print. Obtenido de The Guardian web site.

8. Thompson, E. (1979). La economía "moral" de la multitud en la Inglaterra del siglo XVIII. En E. Thompson, Tradición, revuelta y consciencia de clase (págs. 62-134). Barcelona: Editorial Crítica. 